\title{
EXPLORING THE SOCIO-ECONOMIC IMPACTS OF THE RISE OF AUTOMATION IN BUSINESS
}

\author{
Karan Singhvi \\ Chaminade College Preparatory High School \\ DOI: 10.46609/IJSSER.2020.v05i03.015 URL: https://doi.org/10.46609/IJSSER.2020.v05i03.015
}

\begin{abstract}
Technological advancements have become an integral part of the process of human evolution and social development. The automation of business has led to significant changes not only in the economy but also on the behavior of individuals and narratives of development. The use of artificial intelligence and robotics in jobs conventionally performed by humans has sparked a larger ethical debate surrounding its impact on unemployment, economic inequality, and social progression. This paper has analyzed the impact of technological advancements on the economy in the light of globalization and the emergence of capitalism as the dominant socio-economic narrative. It has also sought to explore the long term implications of moving into a more automated environment based on the social and cultural environment in which nation'-states operate. Growing rates of unemployment and economic inequality and their larger implications on society continue to be some of the major long term challenges faced by policymakers. Lastly, this paper has sought to explore interventions and policy changes- such as the introduction of Universal Basic Income that aim to establish a level playing field in an automated environment.
\end{abstract}

Keywords: Automation in business, Social development, Human evolution, Technologies

\section{INTRODUCTION}

Mankind is on the brink of the Fourth Industrial Revolution in which breakthrough technologies such as artificial intelligence, robotics, data science, quantum computing, and internet-of-things, will enable the development of advanced applications such as social robots, autonomous vehicles, virtual assistants, 3D printing and desktop manufacturing (Vermeulen, et. al., 2018). Automation refers to all technology that enables a process or procedure is performed with minimal human assistance and effort (Groover, 2014). Automation includes a wide range of technology with varying levels of control complexity, ranging from simple on-off controls to 


\section{International Journal of Social Science and Economic Research}

ISSN: $2455-8834$

Volume: 05, Issue: 03 "March 2020"

multivariable high-level algorithms. The basic applications of automation range from devices such as household thermostats that control refrigeration and water heating, to large industrial control systems that include tens of thousands of input measurements and output control signals. The development of automation in the 1930s was one of the most important technological advancements that led to the reduction in the need for labor (Rifkin, 1995). The emergence of robotics and artificial intelligence (AI) since then has fundamentally reshaped not only business processes but also the economy and society. Robotics is an interdisciplinary science that seeks to develop machines that can substitute for humans and replicate human actions. Artificial Intelligence goes a step further and aims to emulate human actions and cognition to take actions that maximize its chance of successfully achieving its predetermined goals. The rise of automation in business traces its cause to reducing the cost, inefficiency, and risk of using human labor in production processes.

There has been significant debate surrounding the overall impact of a more automated world on human behavior and society which is primarily characterized by the anxiety of unemployment. Increased automation has historically caused workers to feel anxious about losing their jobs because of technology rendering their skills and experience unnecessary. Workers have forcefully resisted technological advancement in business since the Industrial Revolution, as inventions like the steam engine started making some job categories expendable. English textile workers protested the introduction of weaving machines by destroying them. Similar movements have sprung up periodically ever since. For most of the nineteenth and twentieth centuries, the most influential labor movements were those that advocated for the retraining of workers whose jobs were rendered redundant by machines (Romero, 2018). The historical correlation between the implementation of technological advancements in business processes and environmental degradation has added a layer of skepticism to the recent developments in artificial intelligence and robotics that has led to an advancement in the level of automation.

However, automation accrues certain benefits for society as a whole in the long run- provided it is accompanied by the correct instruments of state policy. Technological development has historically improved the standard of living of individuals in a particular society. Since the industrial revolution, automation in business has led to a reduction in the cost of production and the availability of commodities at cheaper rates, lower average work hours, and the formation of new industries. One of the biggest positive impacts of the growth of artificial intelligence and automation in the twenty-first century is the development of human capital fueled by the growth of the service sector. The growth in demand for high skilled jobs goes hand in hand with the elimination of low skilled manufacturing jobs. However, the workforce generally lacks the mobility to switch from one set of jobs to another. There is also a need for setting up 


\section{International Journal of Social Science and Economic Research}

ISSN: $2455-8834$

Volume: 05, Issue: 03 "March 2020"

mechanisms that allow for the distribution of economic gains that are achieved as a result of automation to the workforce at large.

\section{BACKGROUND}

Research conducted on the impact of automation on employment has been extensive. Carl Benedikt Frey and Michael Osborne of the Oxford Martin School concluded that automation would lead to the displacement of $47 \%$ of the jobs in the United States because employees engaged in tasks that follow well-defined procedures can easily be replaced by sophisticated algorithms. The jobs most at risk were determined to be low-paid physical occupations that require standard labor inputs (Frey \& Osborne, 2013). A Massachusetts Institute of Technology Economics study conducted in the United States between 1990 to 2007 concluded that the introduction of robots in an industry leads to a negative impact on not only the employment rate but also the wage rate. The introduction of 1 robot to a workforce of 1000 people leads to a reduction in the unemployment rate by $0.18 \%$ and a reduction in wage rate by $0.25 \%$. The growth of automation fueled by the development of $\mathrm{AI}$ and robotics is expected to or quadrupling of the decrease in the employment and wage rate (Acemoglu \& Restrepo, 2018).

Research published in McKinsey Quarterly in 2015 concluded that automation and computerization do not lead to the replacement of employees but the replacement of certain elements of the tasks performed by them, and hence does not negatively impact the employment rate (Chui, et. al., 2015). The impact and need for the development of automation are also dependent on the level of economic development and the demographic composition of a particular country. Whilst growing automation threatens to increase the unemployment rates in countries with a high and increasing population such as India and the United States, the economic development of countries with negative population growth is often contingent on the automation of business processes. The major challenges facing businesses in western Europe, Japan and Korea include a shortage of labor and the lack of willingness to engage in certain professions. The impact of these trends is expected to intensify in the future with the global trend of population aging (Scott Technologies, 2019). The development of technology is expected to not only make up for the lost economic productivity but also to reduce the risk of accidents in the workplace that put the workforce at vulnerable positions and hazardous sites (Scott Technologies, 2019). Research suggests that there is substantial job creation in the quaternary sectors which are generally termed as the 'knowledge-oriented sectors in the economy', personal/health care, luxury goods sectors, and the service sector. Moreover, this job growth is considered to be faster than the average growth in disposable income, and job loss due to automation (Vermeulen, et. al., 2018). Research has also showcased the need for changing curriculum and introducing skill training for the workforce to retain workers and ensure 


\section{International Journal of Social Science and Economic Research}

ISSN: $2455-8834$

Volume: 05, Issue: 03 "March 2020"

employability (McKinsey Global Institute, 2018). Technological unemployment has historically been compensated by a decrease in the average hours worked by the workforce. Empirical evidence shows that unemployment rates have fluctuated but average rates have remained about the same for a century and a half, effectively absorbing major sectoral shifts caused due to growing automation of business processes. Even though this is partly due to the introduction of women in the workforce, there has also been a reduction in the average hours worked by the workforce in developed countries that have experienced high rates of technological advancement (Vermeulen, et. al., 2018).

\section{DISCUSSION}

Automation is a process that has already contributed significantly to unemployment, particularly in nations where the government does not proactively seek to diminish its impact. Research suggests that 47\% of all current jobs In the United States will be fully automated by 2033 .

Wages and educational attainment are strongly negatively correlated with an occupation's risk of being automated. This implies that jobs that require fewer skills and are usually performed by the poor and uneducated class of society face a higher risk of elimination due to automation. The worst impact of automation is thus faced by the socio-economically weaker sections of society. Moreover, the automation of businesses is also characterized as the manifestation of the need of business owners and the capitalist class to earn higher profits. The usage of machines not only reduces the costs and risks involved in manufacturing but also leads to standardization of processes and eliminates human error. Thus, there is often a direct correlation between how automation and profits earned by a business in the long term. To survive in a competitive market, companies have been forced to adopt automation to compete with others who have chosen to do so. This leads to the perpetuation of economic inequality because the benefits of automation, in terms of profit earned by the capitalist class, essentially comes at the cost of employment and reduction in socio-economic mobility of the workforce.

The anxiety faced by labor organizations and workers as a result of automation has been dealt with through strengthening the bargaining power of unions and collectives that enables them to protect the economic interests of the workforce even after automation. Structured organizations go a long way in dispelling myths about unemployment and helping the workforce adjust their skills that enables them to work alongside machines and retain their livelihoods. The relative anxiety about automation reflected in opinion polls seems to correlate closely with the strength of organized labor in that region or nation. For example, while a study by the Pew Research Center indicated that $72 \%$ of Americans are worried about increasing automation in the 


\section{International Journal of Social Science and Economic Research}

ISSN: $2455-8834$

Volume: 05, Issue: 03 "March 2020"

workplace, $80 \%$ of Swedes see automation and artificial intelligence as a good thing, due to the country's still-powerful unions and a more robust national safety net (Goodman, 2017).

It is also argued that automation does not lead to the replacement of human labor, but changes in the tasks performed by individuals. Moreover, the economic development that occurs as a result of automation leads to a higher standard of living and the development of human capital at a rate that allows individuals to access and perform more nuanced and higher quality jobs- that are at least risk of replacement. Research suggests that the demand for unskilled human capital declines at a slower rate than the demand for skilled human capital increases (Saint- Paul, 2012). Even though the number of jobs lost to automation is offset by the jobs it enables to create, the jobs that are lost are not the same as the ones replaced. This puts the economically weaker sections of society at a disadvantage because of their inability to access 'high-quality' jobs. This is known as "income polarization", a process in developed economies where there is a reduction of demand for unskilled labor and an increase in demand for skilled labor. This leads to the further perpetuation of economic inequalities within society.

There has usually existed a trade-off between economic development and environmental protection for societies because economic growth has come at a cost of environmental harm. The impact of automating business on the environment depends on the technology, product or engine automated. There are automated engines that consume more energy resources from the Earth in comparison with previous engines and vice versa. Self-driving vehicles, for example, are precise concerning acceleration and breaking, which contributes to a reduction in emissions. Self-driving cars also utilize fuel-efficient features such as route mapping that enables them to calculate and choose the most efficient routes. Despite this potential to reduce emissions, some researchers theorize that an increase in the production of self-driving cars could lead to a boom of vehicle ownership and use. This boom could potentially negate any environmental benefits of selfdriving cars if a large enough number of people begin driving personal vehicles more frequently. Automation of homes and home appliances is also thought to impact the environment, and a study of energy consumption of automated homes in Finland showed that smart homes could reduce energy consumption by monitoring levels of consumption in different areas of the home and adjusting consumption to reduce energy leaks (such as automatically reducing consumption during the nighttime when activity is low). This study, along with others, indicated that the smart home's ability to monitor and adjust consumption levels would reduce unnecessary energy usage (Louis, et. al. 2015).

\section{CONCLUSION}




\section{International Journal of Social Science and Economic Research}

ISSN: $2455-8834$

Volume: 05, Issue: 03 "March 2020"

The development of artificial intelligence and robotics has taken automation in businesses to a whole new level. Even though there are many benefits of this in the short and long run including safety in the workplace and the general improvement in the standard of living of people fueled by higher economic development. However, this economic development tends to be exclusionary because it can emerge in the form of growing income inequality within the population and higher class conflicts. Even though many new products, services, occupations, and sectors related to these technologies are yet to emerge, there is a need for developing state interventions that would allow for the equitable distribution of economic prosperity.

Firstly, there is a need to introduce policies that seek to regulate the introduction of robotics and Artificial Intelligence by blocking or taxing their implementation. The rationale behind the introduction of these taxes is to help out that part of the workforce that has lost its employment due to automation, computerization, and robotization. However, these taxes acting alone only leads to an increase in the equilibrium wage rate without structurally changing the outcomeunemployment. There is a need to implement these taxes internationally to prevent the shifting of automation from one country to another. There is also a need for the state to actively engage in skill development that allows the workforce to adapt to changes in business caused by technological advancements. This includes training that is required to operate complex technological systems and a curriculum that is more compatible with not only data science and artificial intelligence but also with the growing service and quaternary sector. Lastly, there is a need to formulate and implement systems that seek to redistribute income through policies such as Universal Basic Income. This can be instrumental in meeting the basic and social security needs of that section of the population that loses their livelihoods due to the growth of automation. The financial requirements for implementing these policies can be met through the implementation of taxation on new technological developments discussed above (Vermeulen, et. al., 2018). UBI has already occupied a central position in political discourse in the United States by being the flagship program of Andrew Yang's presidential campaign (Kearney \& Mogstad, 2019). Strengthening labor unions is imperative to introduce progressive legislation.

The automation of business has far-reaching consequences on not only those who directly engage with it but the society as a whole. This implies that there is a fundamental need to reshape and reimagine fundamental markers of development such as education and exposure to technology. The economic gains of automation are undisputed but it is up for the state, businesses, and individuals to ensure that these gains are most equitably distributed amongst all members of society.

\section{BIBLIOGRAPHY}




\section{International Journal of Social Science and Economic Research}

ISSN: $2455-8834$

Volume: 05, Issue: 03 "March 2020"

Acemoglu, D. Restrepo, P. Robots and Jobs: Evidence from US Labor Markets. Accessed on 21st February 2020

Chui, M. Manyika, J., Miremadi, M. (2015). Four fundamentals of workplace automation As the automation of physical and knowledge work advances, many jobs will be redefined rather than eliminated-at least in the short term". McKinsey Quarterly. Accessed on 19th February 2020

Frey, C.B., Osborne, M.A. (2013). The Future of Employment: How Susceptible Are Jobs To Computerization. Accessed on 22th February 2020

Goodman, P. S. The Robots are Coming, and Sweden is Fine. The New York Times., 27th December 2017

Groover, M. (2014). Fundamentals of Modern Manufacturing: Materials, Processes, and Systems. Accessed on 21st February 2020

Kearney, M. \& Mogstad, M. Sorry Andrew Yang, the math is clear: universal basic income is a terrible idea. Business Insider, 23rd November 2019

McKinsey Global Institute. (2018). How will automation affect jobs, skills, and wages. McKinsey, Accessed on 16th February 2020

Louis, J., Antonio, C., Kauko, L., Eva, P. (2015). Environmental Impacts and Benefits of Smart Home Automation: Life Cycle Assessment of Home Energy Management System. Accessed on 22nd February 2020

Rifkin, J. (1995). The End of Work: The Decline of the Global Labor Force and the Dawn of the Post-Market Era. Putnam Publishing Group. Accessed on 21st February 2020

Romero, S. Wielding Rocks and Knives, Arizonans Attack Self-Driving Cars. The New York Times, 31st December 2018

Saint-Paul, G. (2008). Innovation and Inequality: How Does Technical Progress Affect Workers?. Accessed on 21st February 2020

Scott Technology. (2020). The Impact of Automation on Manufacturing. Accessed on 19th February 2020 
International Journal of Social Science and Economic Research

ISSN: $2455-8834$

Volume: 05, Issue: 03 "March 2020"

Vermeulen, B. Kesselhut, J., Pyka, J., Saviotti, P.P. The Impact of Automation on Employment: Just the Usual Structural Change? Sustainability Accessed on 18th February 2020 